\title{
Disabled Future in the Kingdom of Saudi Arabia
}

\author{
Elsheikh, A. S., Alqurashi A.M. \\ Department of Applied Medical Sciences, Community College /Najran University, Saudi Arabia
}

\begin{abstract}
Many people in Saudi Arabia are living with different kinds of disability including learning disability.This number is growing andincreasinglyirritatingasaresultofthe increasingnumberoftrafficaccidentsand the fast advances in technology which increases the learning disabilities. These challengingproblems cannot be faced without proper planning, endorsement of special disability development projects, conducting edge cutting researches on disability and utilizing the modern technologies to collect, record, retrieve and share all the disability data of the different Saudi region. Thus the overall objectives of this article are to provide basic information on disability problems in Saudi Arabia to help service providers to plan, design and execute proper services for the disabled welfare in thefuture.
\end{abstract}

Key words: disability, models, management, development.

\section{Introduction}

The number of disabled adult who are waiting to have a job in Saudi Arabia is estimated to be more than 183000 and those who are capable to work after proper training are about 100000 [1].The social affair representative in Medina estimated the number of disabled to be 720000 , about $4 \%$ of the total Saudi population [2]. Also another estimationof the disabled is 900000 , about more than $8 \%$ of Saudi population [3]. In a demographic survey the number of disabled was said to be $135000,(0.8 \%)$ of the total population [4]. These estimates of the disabled population in Saudi Arabia are neither identical nor they are convergent. The majority of these studies have focused on cross-sectional, community-based epidemiologic studies aimed at finding the prevalence or aetiology of disability [5; 6; 7]. Additionally, these studies ignored the learning disability, which is a great obstacle that faces the community future in a fast changing world that endorsesrecent technologies in all its activities. The learning disability cannot be alleviated without implementing a serious and sustainable policy. Also it is important to move beyond prevalence studies to generate comparative and informative data on the disabled people and their non-disabled peers [8; 9]. The definitions of disability should not be limited to the impairments that diminish the strength, value or quality of individual characteristics, but they should also cover contextual dimensions which contribute, augment or act as a barrier to disable individuals [9]. Recently the term disability incorporates both individual characteristics and social circumstances that interact to create a disabled person [10]. From these studies it is easy to understand that the definition used for the disabled and their real numbers in the country are inappropriate. The number of the disabled is probably far higher than the values estimated, because those who are searching for jobs are not the elderly, children, complex disabled, and never ever most of the disabled women. Also many of the disabled in the rural and some of the urban areas may beignored. The overall objectives of this review are to highlight disability problems and provide basic information to researchers and service providers to help them in managing disability in Saudi Arabia.

\section{Social model of disability}

Physicians look to the human body as a machine to be fixed in order to conform to normative values, thus they define disability type according to the type of impairment. This medical definition is the medical model for disability [11].The social model of disability identifies systemic barriers, negative attitudes and exclusion by society (purposely or inadvertently) that mean society is the main contributory factor in disabling people. Thephysical, sensory, intellectual, or psychological variations, may lead to functional limitation or impairments of individual activities. These do not have to lead to disability unless the society fails to take account of and include people regardless of their individual differences. Thus disability does not mean inability.

\section{Management of the disabled individuals}

Many societies try to change, fix or cure disabled individuals against their wishes. This could be extremely discriminatory. This social activity is as if we say to the disable you will not be of value to your society unless we do this for you. This attitude would be harmful both for the disabled subjects as well as the community. In many communities the people try to help the disabled according to what they need from them to be. However, the concerned persons may not like this[12]. People with an autism spectrum disorderconsider them selfas neurodiversityaccommodated to different purposes in the society, thus they oppose efforts to make 
them like the others [13]. Similarly, those with mental disorder and deafness they might resist curing them thinking that they are just different and don't need to conformto others[14]. The terminologies we used to describe the disabled are really rubbishthat through away all the important and beautiful things the disabled can do.The disabled are people with unique abilities,therefore it is in judicial to allow ourselves to depersonalize, mask,ignore their individualities, and deny their rightsas human beings.Accordingly the society should differentiate between impairment and disability. Impairment describes the abnormalities of the locomotion system, nervous system,vision, hearing, psychological defects, neoplasm, cardiovascular disorders, as well as defects caused by mal-nutrition and any other ailments thatimpair the human being. Disability is a term that means the restrictions caused by the society when it fails to accommodate the needs of the impaired individuals [15]. Socially disability relates to economics, if there are no resources to meet theneeds of the peoples definitely they will be disabled. The disabled could contribute to the economy equally as his peers, if he is furnished with the same facilities and given equal opportunities as his peers have. Therefore, when managing the individuals with impairments, the society should not use destructive terminologies, ignore, depersonalize, or deny their rights. Furthermore, the concerned authorities should strive and struggle very hard to find accommodation for their needs and to find new terminologies to describe their impairments without hurting them in order to integrate them into the society.

\section{Disabled abilities}

As it was mentioned above disability does not mean inability.Many disabled were able to overcome their disability and led themselves to be among the greatest people of all time. Abraham Lincoln, the sixteenth president of the United States, suffered melancholia a form of today's depression,similarly the former president of Russia Boris Yeltsinsuffered depression[16]. Ludwig Van Beethoven - Beethoven was as we know a great source of confidence for himself and for others, being able to create music and play music even after being completely deaf is by itself quite a miracle (Disabled world 2006). Of course any Muslim knows that the prophet and apostil of Allah, Musa (peace be upon him), had pronouncing disability. This was confirmed in the thirteen verse of Surratt Alshuara (the holy Quran) which means (My chest become narrow nor my tongue utter, Oh Lord send to me Haroun).In the Arab countries there are many known individuals who were born with various impairments, however, they overcome them. The famous example is the Egyptian Dr.Taha Hussein who was born blind. These facts confirm that theindividuals with impairments have unique characteristics, creative and have potentials not found in their peers.

\section{Disabled rights}

Disability Discrimination Act 1995 (DDA) gives the disabled individuals manyrights, likeaccess to goods, facilities, services and premises[17].Thus, service providersmustnot treatthedisableddifferentlyfromnondisabledpersonsbecause oftheir disability. The service providers have had to take reasonable steps to change practices, policies and procedures which make it impossible or unreasonably difficult for disabled people to use a service. They have had to provide auxiliary aids or services which would make it easier and/orenablethe disabled people to use a service; and to overcome physical features, which make it impossible or unreasonably difficult for disabled people to use a service, by providing the service by a reasonable alternative method.

Many facilities and services in the pedestrian environment and in transport related infrastructure: bus stations and stops, airports and high buildings, stadium, squares and gardens should be availed. All the premises should be designed to meet the needs of the disabled people.These are not all the rights ofthe disabled,butthemostimportantright that must be taken into account is to treat them a treatment similar to their peersandhavetheright to workand decent livingwithoutmaking them feelhelpless.

\section{Disabled development}

In all the Arab countries the needs of individuals who suffered impairments are almost ignored during implementation of development plans. If correct and adequate data of disability is collected and identified early; planners will find it easy to create projects suitable for the disabled people in future. The communities should have to think to utilize these individuals before they found themselves obliged to do so, when the number of this group become enormous and its accommodation in the different activities becomes extremely difficult, if not impossible. This category of the society if include in all development projects definitely it will add a lot to the national economy and it will not be a burden on the society. In Saudi Arabia more than 100000disabled individuals with different types of impairments are currently awaiting to have jobs [1]. There are no national or private projects that can accommodate them. If no fast and adequate plans were done to solve this problem, the number will increase. Consequently, the situation will explode and the international organizations that sponsor the disabled needs, will try to intervene to resolve the crisis. The risksandproblemsthat accompanytheinterventionoftheseorganizationsare well known. Therefore, quick and fast steps to solve the present problem and the expected future problems should be taken. 


\section{Demographic studies}

The disability status in the kingdom of Saudi Arabia necessitates conduction of demographic studies that cover all the regions of the kingdom to record all the kinds of disability and their socioeconomic impacts. Studies that utilise questionnaires, the available data in hospitals, primary health care centres, research data and data available in the Ministry of Health and related organizations. The questionnaires should be designed to cover all the facets of disability including aetiology, learning and contextual causes [9, 18].The community should be classed into social groups based on the long occupation attended (if any).The women should be classed and assigned to social groups based on their occupation rather than their husband's occupation. The level of education should be considered to distinguish the learning disability particularly individuals who are not able to utilise the modern technologies such as computer. The house tenure should not be ignored because it gives idea about the income. Those who live in tent are not like those who lives in apartments or villas. The source of income, age, sex, and marital status are undoubtedly useful.

\section{Researches on disability causes}

Many factors can causes, enables or augment disability such ascommunicable diseases (poliomyelitis); hereditary (muscle dystrophy); nutritional disorders (deficiencies of protein; minerals and vitamins); injuries (traffic accident); malignant neoplasms; neuropsychiatric conditions; cardiovascular conditions and diabetes mellitus. Many of the leading diseases that enable disability (lower respiratory infections, diarrheal diseases, perinatal disorders, unipolar major depression, ischemic heart disease, cerebrovascular disease, tuberculosis, measles, and congenital anomalies) are attributable to childhood malnutrition, poor water, and sanitation and personal and domestic hygiene[19].Nor can we ignore some of community customs and traditions like relative marriages that lead to inbreeding. Also recently a correlation between autism, neurodevelopment disabilities and environment was discovered [20]. Thus the researches in the kingdom should be directed to elucidated, treat and prevent the occurrence of disability.

\section{Obstacles facing disability researches}

Many difficulties face researchers who work in this field in SaudiArabia. The Saudi society is characterized by high incidence of inbreeding due to relative marriages [21;22].The high incidence of car accidents and the refrain of the families who have a disabled childto participate in such research is one of the causes [22]. The most crucial cause is the lack of appropriate demographic studies on disability. Such researcheswill enable us to answer all the questions about the types, the aetiologies, incidences of disability and their socioeconomic impact on the Saudi society. Most of researches done are surveys [23; 24; 25; 26; 27]. Edge cutting researches in this field are very important to reduce, treat or event to prevent the occurrence of many types of disability.

Multidisciplinary researches, in which different specialist participate including all the related fields and statisticians should be planned for proper experimentation, variables arrangement, sample collection, data analysis, and proper interpretations of the researches outcomes. Therefore, major projects on disability should be launched and financially supported by the government and/or the national scientific organizations. Undoubtedly, the establishment of additionallyspecialized institutes (like prince Salman Center for Research in Disability) in all Saudi regions,to follow-up these researches is a must.

\section{Disability Databases systems}

The decision makers and those who are in charge of disability management in Saudi Arabia should have to think to construct database system of information for all the regions of the country. All the hospitals, health care centers, concerned authorities;and research institutes should have an access to this disability database system. The database system should record all the necessary information about disability, its causes and its incidence. These databases will help the decision-makers to plan to cure and accommodate the impaired individuals. The concerned individuals can make use of this data to know the projects and plans launched to serve them.

\section{Conclusions}

1. The realnumber of disabled personscannot bedeterminedaccuratelydue to the highrateofaccidentsandthe dailydeliverieswhichrequirea technicalinformationsystem (Database system)to facilitateandacceleratetheprocessof recording, retrieving, and monitoringdisability data.

2. The learning disability, which is a great obstacle that faces the community future in a fast changing world that endorse recent technologies in all its activities, must not be ignored.

3. When managing the individuals with impairments, the society should not use destructive terminologies, ignore, depersonalize, or deny their rights. 
4. The concerned authorities should strive and struggle very hard to find accommodation for needs of the disabled and to find new terminologies to describe their impairments without hurting them in order to integrate them into the society.

5. The disability status in the kingdom of Saudi Arabia necessitates conduction of demographic studies that cover all the regions of the kingdom to record all the kinds of disability, their causes, and their socioeconomic impacts.

6. Multidisciplinaryedge cutting researches in this field; particularly on hereditary and physical causes; are very important to reduce, treat or event to prevent the occurrence of many types of disability.

\section{References}

[1]. C. Trenwith. Saudi looks to put 100,000 disabled people in jobs. Arabian business.com. Midline article, 2013.

[2]. Arab news. KSA has 720000 disabled. Medline article, 202.

[3]. English.news.cn. Number of handicapped in Saudi Arabia up by 8\%. Midline. Article, 2012

[4]. M.S.Al-Jadid. Disability in Saudi Arabia Saudi Med J; Vol. 34 (5), 2013, 453-460.

[5]. S.A. Ansari, F. Akhdar. Prevalence of child disability in Saudi Arabia Disability Rehabilitation, 20, 1998, $25-28$.

[6]. W. R. Murshid, M.A.M. Salih, J.S. Jarallah. Epidemiological Research on Neural Tube Defects in Saudi Arabia: Incidence, Degree of Disability, and Etiology. Midline article, 2003.

[7]. A. Al-Shehri, M. M. Abdel-Fattah. Disability among clientsattending TaifRehabilitation Centre, Saudi Arabia.Asia Pacific Disability Rehabilitation Journal,Vol. 19 No. 2 2008, 50-62.

[8]. D. Mont. Measuring disability prevalence. Washington (DC): World Bank, 2007.

[9]. D. E. Simikiss, C.M. Blacburn, F. O. Mukoro, J. M. Read, N.J. Spencer, Childhood disability and socio-economic circumstances in low and middle income countries: systematic review. BMC Paediatrics, 11:119 doi: 10.1186/1471-2431-11-119, 2011.

[10]. G. Stuck, A. Boonen, P. Tugwell, A. Cieiza, M. Boer. The World Health Organization International Classification of Functioning, Disability and Health: A Conceptual Model and Interface for the OMERACT Process. The Journal of Rheumatology, 2007, 34:3.

[11]. J. Paley. The Cartesian melodrama in nursing. Nursing Philosophy3 (3): 189-192. doi:10.1046/j.1466-769X, 2002, 00113.x.

[12]. NASEO. Sound from Silence - Sidebar - Cochlear Implant. Beyonddiscovery.org. Midline article, 2012.

[13]. K.Seidel (2004). The autistic distinction. Neurodiversity.com. Medline article, 2004.

[14]. G. Engel. The need for a new medical model: a challenge for biomedicine. Science 196 (4286), 1977, 129-136.

[15]. T. Pam, G. Lorraine, M. Natalie. . Defining Impairment within the Social Model of Disability. leeds.ac.uk, Midline article, 2012.

[16]. Disabled World. A list of some famous and well known people with various disabilities and conditions including actors, politicians and writers who contributed to society. Medline article, 2006.

[17]. The Disability Discrimination Act 1995 with 2005 amendmentscontents, Midline article.

[18]. E. Grundy, K. Glaser. Socio-demographic differences in the onset and progression of disability in early old age: a longitudinal study. Age and Aging, 29, 2000, 149-157.

[19]. J. L. M. Christopher, A. D. Lopez. Global mortality, disability, and the contribution of risk factors: Global Burden of Disease Study. The Lancet, 349, Issue 9063, 1997, 1436 - 1442.

[20]. P. J. Landrigan, L.Lambertini, L.S. Birnbaum. A Research Strategy to Discover the Environmental Causes of Autism and Neurodevelopmental Disabilities.Environ Health Prospect. 120(7), 2012, 258-260.

[21]. M. Al- Essa, P.T. Ozand, S.I. Al-Gain. Awareness of inborn error of metabolism among parents in Saudi Arabia. Ann Saudi Med. $17,1997,562-564$.

[22] S. I. Al-Gain, S.S. Al-Abdulwahab. Issues and obstacles in disability research in Saudi Arabia. Asia Pacific Disability RehabilitationJournal, 13, 2002, 45-49.

[23]. M. Alsekait. The incidence of disability in Al Qaseem. Riyadh (KSA): Prince Salman Centre for Disability Research, Midline article1993.

[24]. M. A. F. El-Hazmi. Early recognition and intervention for prevention of disability and its complications. Eastern Mediterranean Health Journl, 3 (1)1997, 154-161.

[25]. M. Al-Turaiki, M. National Survey of disability and rehabilitation in Saudi Society. Riyadh (KSA): The Joint Centre for Research in Prosthetics Orthotics, Midline article 2000.

[26]. M. A. El-Hazmi, A. A. Al-Swailem, N. A. Al-Mosa, A. A. Al-Jarallah. Prevalence of mental retardation among children in Saudi Arabia. East Mediterr Health Journal, 9, 2003, 6-11.

[27]. M. B. Al-Hazmy, B, Al Sweilan, N.B. Al-Moussa. Handicap among children in Saudi Arabia: prevalence, distribution, type, determinants and related factors]. East Mediterr. Health Journal, 10, 2004, 502-521. 